\title{
PRNP genetic variability and molecular typing of natural goat scrapie isolates in a high number of infected flocks
}

\author{
Eirini G Fragkiadaki ${ }^{*}$, Gabriele Vaccari ${ }^{2}$, Loukia V Ekateriniadou' ${ }^{1}$ Umberto Agrimi ${ }^{2}$, Nektarios D Giadinis ${ }^{3}$, \\ Barbara Chiappini², Elena Esposito ${ }^{2}$, Michela Conte ${ }^{2}$ and Romolo Nonno ${ }^{2}$
}

\begin{abstract}
One hundred and four scrapie positive and 77 negative goats from 34 Greek mixed flocks were analysed by prion protein gene sequencing and 17 caprine scrapie isolates from 11 flocks were submitted to molecular isolate typing. For the first time, the protective S146 variant was reported in Greece, while the protective K222 variant was detected in negative but also in five scrapie positive goats from heavily infected flocks. By immunoblotting six isolates, including two goat flockmates carrying the K222 variant, showed molecular features slightly different from all other Greek and Italian isolates co-analysed, possibly suggesting the presence of different scrapie strains in Greece.
\end{abstract}

\section{Introduction, Methods and Results}

Scrapie is a prion disease that affects sheep and goats. It belongs to the group of transmissible spongiform encephalopathies (TSE) that also comprises the zoonotic bovine spongiform encephalopathy (BSE). Major determinants for sheep scrapie occurrence have been demonstrated to be the host susceptibility, regulated mainly by the prion protein encoding gene (PRNP) [1,2] and the prion strain [3]. However, the association of genetic variability of goat $P R N P$ with resistance to TSE is still under investigation $[4,5]$ and limited knowledge is available on natural goat prion strains [4,6-8]. Greece has the largest goat population in Europe [5], mainly bred in mixed flocks, and the second higher prevalence of goat scrapie (175 scrapie positive goats over 40034 tested during 2002-2008) [9]. In this study PRNP coding sequence of Greek goats, from both scrapie affected and healthy goats was investigated, in regards to their gene variability. However, due to the lack of appropriate sampling of negative goats, this work is not a case control study. Molecular strain typing by discriminatory western

\footnotetext{
* Correspondence: eirfrag@gmail.com

'National Agricultural Research Foundation, Veterinary Research Institute, Thessaloniki, Greece

Full list of author information is available at the end of the article
}

blotting (WB) was also implemented on $\sim 10 \%$ of the scrapie positive goats detected between 2002 and 2008.

Among samples diagnosed at the Greek National Reference Laboratory for TSE, by using TeSeE BIORAD and TeSeE Western Blotting BIORAD, archived frozen obex tissues from 106 positive (derived from 34 flocks from 13 geographic areas) and 77 negative goats (collected from five flocks with high scrapie prevalence) were submitted to genotyping analysis (Table 1). Most goats were asymptomatic except for three clinical suspects, and one that appeared suspect at slaughter (Table 2). The mean age of scrapie tested goats was around 36 months (ranging from 12 to 86 months).

Genotyping was performed as previously described $[10,11]$. Two samples gave no PCR amplification and the analysis of the remaining 104 samples revealed 37 PRNP genotypes (Table 1). Twenty polymorphic codons and an octapeptide deletion polymorphism were detected. Sixteen polymorphisms resulted into amino acid substitutions at codons G37V, T110P, G127S, A136T, I142M, H143R, N146S, R151H, R154H/Q, P168Q, S173N, R211Q, Q222K, S239F, S240P, while 5 were silent nucleotide polymorphisms (codons 42 $c c a \rightarrow c c g$; 138 agc $\rightarrow$ agt, 231 agg $\rightarrow c g g, 237 c t c \rightarrow c t g$ and $238 t t t \rightarrow t t c)$. In 177 out of 181 goats, five octapeptide repeats between codons 54-95 were observed, while in
C Biomed Central

(c) 2011 Fragkiadaki et al; licensee BioMed Central Ltd. This is an Open Access article distributed under the terms of the Creative Commons Attribution License (http://creativecommons.org/licenses/by/2.0), which permits unrestricted use, distribution, and reproduction in any medium, provided the original work is properly cited. 
Table 1 PRNP genotypes of scrapie positive and negative goats ${ }^{1}$.

\begin{tabular}{|c|c|c|c|c|c|c|c|c|c|c|c|c|c|c|c|c|c|c|c|}
\hline \multirow[b]{2}{*}{$\begin{array}{c}\text { PrP } \\
\text { genotype }\end{array}$} & \multicolumn{16}{|c|}{ PRNP codon } & & \multicolumn{2}{|c|}{$\begin{array}{c}\text { Number of goats per } \\
\text { genotype }\end{array}$} \\
\hline & 37 & $54-95$ & 110 & 127 & 136 & 142 & 143 & 146 & 151 & 154 & 168 & 173 & 211 & 222 & 239 & 240 & & $\begin{array}{l}\text { Scrapie } \\
\text { positive }\end{array}$ & $\begin{array}{c}\text { Scrapie } \\
\text { negative }\end{array}$ \\
\hline 1 & GG & 5OR:5OR & $\pi$ & GG & $\mathrm{AA}$ & $\|$ & $\mathrm{HH}$ & NN & $\mathrm{RR}$ & RR & PP & SS & $\mathrm{RR}$ & QQ & SS & PP & & 44 & 12 \\
\hline 2 & GG & 5OR:5OR & $\pi$ & GG & AA & $\|$ & $\mathrm{HH}$ & NN & $\mathrm{RR}$ & RR & PP & SS & $\mathrm{RR}$ & QQ & SS & PS & & 30 & 23 \\
\hline 3 & GG & 5OR:5OR & $\pi$ & GG & $\mathrm{AA}$ & $\|$ & $\mathrm{HH}$ & NN & $\mathrm{RR}$ & $\mathrm{RR}$ & PP & SS & RR & QQ & SS & SS & & 9 & 3 \\
\hline 4 & GG & 5OR:5OR & $\pi$ & GG & $\mathrm{AA}$ & $\|$ & $\mathrm{HH}$ & NN & RR & $\neq \mathrm{RH}$ & PP & SS & $\mathrm{RR}$ & QQ & SS & PS & & 4 & 3 \\
\hline 5 & GG & 5OR:5OR & $\pi$ & GG & AA & $\|$ & $\mathrm{HH}$ & NN & RR & $\neq \mathrm{RH}$ & PP & SS & RR & QQ & SS & SS & & 2 & 2 \\
\hline 6 & GG & 5OR:5OR & $\pi$ & GG & $\mathrm{AA}$ & $\|$ & $\mathrm{HH}$ & NN & RR & $\mathrm{RR}$ & PP & SS & $\mathrm{RR}$ & $\neq \mathrm{QK}$ & SS & PS & & 1 & 2 \\
\hline 7 & GG & 5OR:5OR & $\pi$ & $\neq \mathrm{GS}$ & $\mathrm{AA}$ & $\neq \mid M$ & $\mathrm{HH}$ & NN & $\mathrm{RR}$ & RR & PP & SS & $\mathrm{RR}$ & $\mathrm{QQ}$ & SS & PP & & 1 & 1 \\
\hline 8 & GG & *5OR:4OR & $\pi$ & GG & $\mathrm{AA}$ & $\|$ & $\mathrm{HH}$ & NN & $\mathrm{RR}$ & RR & PP & SS & $\mathrm{RR}$ & QQ & SS & PP & & 3 & \\
\hline 9 & GG & 5OR:5OR & $\neq \mathrm{TP}$ & GG & AA & $\|$ & $\mathrm{HH}$ & NN & $\mathrm{RR}$ & RR & PP & SS & RR & $\neq \mathrm{QK}$ & SS & SS & & 3 & \\
\hline 10 & GG & 5OR:5OR & $\pi$ & GG & †AT & $\|$ & $\mathrm{HH}$ & NN & $\mathrm{RR}$ & RR & PP & SS & $\mathrm{RR}$ & QQ & SS & SS & & 1 & \\
\hline 11 & GG & 5OR:5OR & $\pi$ & GG & $\mathrm{AA}$ & $\|$ & $\mathrm{HH}$ & NN & $\mathrm{RR}$ & tRQ & PP & SS & $\mathrm{RR}$ & QQ & SS & PP & & 1 & \\
\hline 12 & GG & 5OR:5OR & $\pi$ & GG & $\mathrm{AA}$ & $\|$ & $\mathrm{HH}$ & NN & $\neq \mathrm{RH}$ & $\mathrm{RR}$ & PP & SS & RR & QQ & SS & PS & & 1 & \\
\hline 13 & GG & 5OR:5OR & $\pi$ & GG & $\mathrm{AA}$ & $\|$ & $\mathrm{HH}$ & NN & $\mathrm{RR}$ & $\mathrm{RR}$ & $\neq \mathrm{QQ}$ & SS & RR & QQ & SS & PP & & 1 & \\
\hline 14 & GG & 5OR:5OR & $\pi$ & $\neq \mathrm{GS}$ & $\mathrm{AA}$ & $\|$ & $\mathrm{HH}$ & $\mathrm{NN}$ & $\mathrm{RR}$ & $\neq \mathrm{RH}$ & PP & SS & RR & $\mathrm{QQ}$ & SS & PS & & 1 & \\
\hline 15 & GG & 5OR:5OR & $\Pi$ & GG & $\mathrm{AA}$ & $\neq \mid M$ & $\mathrm{HH}$ & $\mathrm{NN}$ & $\mathrm{RR}$ & $\mathrm{RR}$ & PP & SS & RR & $\mathrm{QQ}$ & SS & PS & & 1 & \\
\hline 16 & GG & 5OR:5OR & $\Pi$ & GG & $\mathrm{AA}$ & $\|$ & $\mathrm{HH}$ & NN & $\mathrm{RR}$ & RR & PP & SS & RR & $\neq \mathrm{QK}$ & SS & SS & & 1 & \\
\hline 17 & GG & 5OR:5OR & $\neq \mathrm{TP}$ & GG & $\mathrm{AA}$ & $\|$ & $\mathrm{HH}$ & NN & RR & RR & PP & SS & RR & $\mathrm{QQ}$ & SS & PS & & & 5 \\
\hline 18 & GG & 5OR:5OR & $\Pi$ & GG & $\mathrm{AA}$ & $\|$ & $\mathrm{HH}$ & NN & $\mathrm{RR}$ & RR & $\neq P Q$ & SS & $\mathrm{RR}$ & $\mathrm{QQ}$ & SS & PS & & & 3 \\
\hline 19 & GG & 5OR:5OR & $\pi$ & GG & $\mathrm{AA}$ & $\|$ & $\mathrm{HH}$ & $\neq N S$ & $\mathrm{RR}$ & RR & PP & SS & $\mathrm{RR}$ & $\mathrm{QQ}$ & SS & PP & & & 2 \\
\hline 20 & GG & 5OR:5OR & $\pi$ & GG & $\mathrm{AA}$ & $\|$ & $\mathrm{HH}$ & $\neq N S$ & RR & RR & PP & SS & RR & $\mathrm{QQ}$ & SS & PS & & & 2 \\
\hline 21 & GG & 5OR:5OR & $\pi$ & GG & $\mathrm{AA}$ & $\|$ & $\mathrm{HH}$ & NN & RR & RR & $\neq \mathrm{PQ}$ & SS & $\mathrm{RR}$ & QQ & SS & PP & & & 2 \\
\hline 22 & GG & 5OR:5OR & $\pi$ & $\neq \mathrm{GS}$ & AA & $\|$ & $\mathrm{HH}$ & NN & $\mathrm{RR}$ & RR & PP & SS & $\mathrm{RR}$ & $\mathrm{QQ}$ & SS & PP & & & 2 \\
\hline 23 & GG & 5OR:5OR & $\pi$ & GG & $\mathrm{AA}$ & $\|$ & $\mathrm{HH}$ & $\mathrm{NN}$ & RR & RR & PP & SS & $\neq \mathrm{RQ}$ & $\neq \mathrm{QK}$ & SS & SS & & & 1 \\
\hline 24 & GG & *5OR:4OR & $\pi$ & GG & $\mathrm{AA}$ & $\|$ & $\mathrm{HH}$ & NN & RR & $\mathrm{RR}$ & PP & SS & $\mathrm{RR}$ & $\mathrm{QQ}$ & SS & PS & & & 1 \\
\hline 25 & GG & 5OR:5OR & $\pi$ & GG & $\mathrm{AA}$ & $\|$ & $\neq \mathrm{HR}$ & NN & RR & $\neq \mathrm{RH}$ & PP & SS & $\mathrm{RR}$ & QQ & SS & PS & & & 1 \\
\hline 26 & GG & 5OR:5OR & $\pi$ & GG & $\mathrm{AA}$ & $\|$ & $\neq \mathrm{HR}$ & NN & $\mathrm{RR}$ & $\mathrm{RR}$ & PP & SS & $\mathrm{RR}$ & QQ & SS & PP & & & 1 \\
\hline 27 & GG & 5OR:5OR & $\pi$ & GG & $\mathrm{AA}$ & $\|$ & $\neq \mathrm{HR}$ & NN & $\mathrm{RR}$ & RR & PP & SS & $\mathrm{RR}$ & QQ & SS & PS & & & 1 \\
\hline 28 & GG & 5OR:5OR & $\ddagger \mathrm{TP}$ & GG & $\mathrm{AA}$ & $\|$ & $\mathrm{HH}$ & NN & $\mathrm{RR}$ & RR & $\neq P Q$ & SS & $\mathrm{RR}$ & QQ & SS & PS & & & 1 \\
\hline 29 & GG & 5OR:5OR & $\pi$ & GG & $\mathrm{AA}$ & $\|$ & $\mathrm{HH}$ & NN & RR & RR & PP & $+S N$ & $\mathrm{RR}$ & QQ & SS & PP & & & 1 \\
\hline 30 & GG & 5OR:5OR & $\pi$ & GG & $\mathrm{AA}$ & $\|$ & $\mathrm{HH}$ & NN & RR & RR & PP & SS & $\mathrm{RR}$ & $\mathrm{QQ}$ & tFF & SS & & & 1 \\
\hline 31 & GG & 5OR:5OR & $\pi$ & GG & $\mathrm{AA}$ & $\|$ & $\mathrm{HH}$ & NN & $\mathrm{RR}$ & RR & $\neq \mathrm{PQ}$ & $\neq \mathrm{SN}$ & $\mathrm{RR}$ & QQ & SS & PP & & & 1 \\
\hline 32 & GG & 5OR:5OR & $\pi$ & GG & $\mathrm{AA}$ & $\|$ & $\mathrm{HH}$ & fNS & $\mathrm{RR}$ & RR & $\neq \mathrm{PQ}$ & SS & $\mathrm{RR}$ & QQ & SS & PP & & & 1 \\
\hline 33 & GG & 5OR:5OR & $\pi$ & GG & $\mathrm{AA}$ & $\|$ & $\mathrm{HH}$ & $\neq S S$ & RR & RR & PP & SS & $\mathrm{RR}$ & QQ & SS & PP & & & 1 \\
\hline 34 & $\neq \mathrm{GV}$ & 5OR:5OR & $\pi$ & GG & $\mathrm{AA}$ & $\|$ & $\mathrm{HH}$ & NN & $\mathrm{RR}$ & RR & PP & SS & $\mathrm{RR}$ & QQ & SS & SS & & & 1 \\
\hline 35 & $\neq \mathrm{GV}$ & 5OR:5OR & $\pi$ & $\neq \mathrm{GS}$ & $\mathrm{AA}$ & $\|$ & $\mathrm{HH}$ & NN & RR & RR & PP & SS & $\mathrm{RR}$ & QQ & SS & PS & & & 1 \\
\hline 36 & $\neq \mathrm{GV}$ & 5OR:5OR & $\pi$ & $\neq \mathrm{GS}$ & $\mathrm{AA}$ & $\|$ & $\mathrm{HH}$ & $\mathrm{NN}$ & RR & RR & PP & SS & $\mathrm{RR}$ & QQ & SS & SS & & & 1 \\
\hline \multirow[t]{2}{*}{37} & $\neq \mathrm{GV}$ & 5OR:5OR & $\pi$ & GG & $\mathrm{AA}$ & $\|$ & $\mathrm{HH}$ & NN & RR & RR & PP & SS & $\mathrm{RR}$ & $\mathrm{QQ}$ & SS & PS & & & 1 \\
\hline & & & & & & & & & & & & & & & & & $\begin{array}{c}\text { Total } \\
(n)\end{array}$ & 104 & 77 \\
\hline
\end{tabular}

1*5OR = five octapeptide repeats, $4 \mathrm{OR}=$ four octapeptide repeats, t: novel polymorphisms observed in goats, $\neq:$ PRNP polymorphisms differing from the wild-type goat.

four goats (3 scrapie-positive and one scrapie-negative) a $24 b p$ deletion was detected between codons 70-77, resulting in four octapeptide repeats [12] instead of the usual three or five repeats reported in goats [13]. For the first time, codon 136 was observed as polymorphic in the goat. Interestingly, this polymorphism, $A 136 T$, is the same observed very rarely in sheep in Greece [14]. It is noteworthy that an additional novel polymorphism in goats, $R 154$ Q, was observed. These two polymorphisms were observed in single scrapie-positive goats. Two novel amino-acid polymorphisms were also observed in negative goats, $S 173 N$ and $S 239 F$. The $S 146$ variant, associated with scrapie protection in Cyprus [12,15], was observed only in negative goats from two different 
Table 2 Natural scrapie isolates analysed with discriminatory western blotting by using mAbs P4 and SAF84².

\begin{tabular}{|c|c|c|c|c|c|c|c|c|c|c|c|c|c|}
\hline Sample's ID & PRNP genotype & Target group & Age (months) & rel ratio & SD & $\mathrm{mw}$ & SD & dig & SD & mono & SD & non & SD \\
\hline GR-L1-G1 & $w t, 240 P / P$ & sl & 21 & 1.21 & 0.35 & 17.54 & 0.17 & 50 & 2 & 31 & 1 & 19 & 3 \\
\hline GR-D1-G1 & $w t, 240 P / P$ & sl & 86 & 0.63 & 0.19 & 17.70 & 0.02 & 52 & 1 & 32 & 1 & 16 & 2 \\
\hline GR-E1-G1 & $w t, 168 \mathrm{Q} / \mathrm{Q}, 240 \mathrm{P} / \mathrm{P}$ & sl & 40 & & & & & & & & & & \\
\hline GR-B1-G1 & $w t, 240 \mathrm{P} / \mathrm{S}$ & sl & 58 & 1.15 & 0.41 & 17.54 & 0.08 & 53 & 2 & 33 & 5 & 14 & 4 \\
\hline GR-M1-G1 & no amplicon & sl & 43 & 1.21 & 0.21 & 17.60 & 0.17 & 53 & 1 & 30 & 3 & 17 & 4 \\
\hline GR-N1-G1 & no amplicon & sl & 20 & 1.05 & 0.09 & 17.57 & 0.16 & 52 & 2 & 32 & 2 & 17 & 3 \\
\hline GR-F1-G1 & $w t, 240 P / P$ & sl & 75 & 0.97 & 0.19 & 17.67 & 0.10 & 52 & 1 & 30 & 2 & 18 & 4 \\
\hline GR-A9-G1 & $w t, 240 P / P$ & sl & 48 & 1.11 & 0.12 & 17.62 & 0.11 & 54 & 1 & 30 & 3 & 16 & 4 \\
\hline GR-A4-G1 & $w t, 240 P / S$ & sl & 36 & 1.02 & 0.28 & 17.59 & 0.02 & 55 & 1 & 29 & 2 & 16 & 3 \\
\hline GR-A4-G2 & $w t, 240 P / P$ & sl & 36 & 0.93 & 0.22 & 17.59 & 0.12 & 54 & 2 & 30 & 3 & 16 & 4 \\
\hline GR-A4-G3 & $w t, 240 P / P$ & sl & 36 & 0.84 & 0.09 & 17.62 & 0.12 & 51 & 3 & 31 & 3 & 17 & 6 \\
\hline GR-A4-G4 & $w t, 240 P / P$ & sl & 24 & 0.85 & 0.16 & 17.61 & 0.12 & 52 & 2 & 30 & 2 & 18 & 3 \\
\hline GR-A4-G5 & $w t, 240 P / P$ & susp. sl & 48 & 1.10 & 0.07 & 17.58 & 0.11 & 50 & 2 & 31 & 2 & 18 & 3 \\
\hline GR-A4-S1 & wt & sl & - & 1.01 & 0.13 & 17.59 & 0.10 & 49 & 2 & 34 & 3 & 16 & 4 \\
\hline GR-A11-G1 & $w t, 240 P / P$ & susp. flock & 24 & 0.61 & 0.12 & 17.72 & 0.03 & 52 & 2 & 32 & 2 & 16 & 5 \\
\hline GR-A11-G2 & $w t, 240 \mathrm{P} / \mathrm{S}$ & susp. flock & 26 & 0.58 & 0.08 & 17.82 & 0.10 & 53 & 4 & 29 & 3 & 18 & 4 \\
\hline GR-A11-S1 & $w t$ & susp. flock & 9 & 0.41 & 0.01 & 17.96 & 0.10 & 48 & 2 & 31 & 0 & 21 & 1 \\
\hline GR-A11-S2 & $A R Q / T R Q$ & susp. flock & 9 & 0.41 & 0.02 & 17.92 & 0.06 & 48 & 4 & 32 & 1 & 20 & 3 \\
\hline GR-A2-G1 & $w t, 222 \mathrm{Q} / \mathrm{K}, 240 \mathrm{~S} / \mathrm{S}$ & sl & 36 & 0.38 & 0.01 & 18.03 & 0.07 & 48 & 2 & 35 & 1 & 17 & 1 \\
\hline GR-A2-G2 & $w t, 222 Q / K, 240 S / P$ & sl & 36 & 0.50 & 0.03 & 18.04 & 0.02 & 48 & 2 & 33 & 2 & 19 & 4 \\
\hline IT1-goat & $w t, 240 \mathrm{P} / \mathrm{S}$ & - & - & 0.98 & 0.05 & 17.56 & 0.11 & 48 & 2 & 31 & 3 & 20 & 3 \\
\hline IT2-goat & $w t, 240 \mathrm{P} / \mathrm{S}$ & - & - & 0.90 & 0.03 & 17.52 & 0.07 & 49 & 2 & 34 & 3 & 17 & 4 \\
\hline IT3-goat & $w t, 240 P / S$ & - & - & 0.87 & 0.17 & 17.51 & 0,04 & 53 & 3 & 30 & 2 & 17 & 1 \\
\hline IT4-goat & $w t, 240 P / P$ & - & - & 1.05 & 0.07 & 17.56 & 0.06 & 52 & 4 & 29 & 1 & 19 & 3 \\
\hline IT5-sheep & $w t$ & - & - & 1.00 & & 17.59 & 0.07 & 52 & 3 & 31 & 2 & 17 & 3 \\
\hline sheep BSE & $w t$ & $\exp$ & - & 8.58 & 1.85 & 16.78 & 0.07 & 71 & 4 & 20 & 2 & 9 & 3 \\
\hline
\end{tabular}

${ }^{2}$ Sample's ID indicates the country of origin (GR for Greece, IT for Italy), the geographic area of origin (alphabetical letters), the flock from that area (i.e. A1) and the number of the goat $(\mathrm{G})$ or sheep ( $\mathrm{S}$, in italics)-cases from the same flock (G1), i.e. GR-A1-G1. Abbreviations: wt: $A R Q / A R Q$ wild type, sl: slaughtered, susp.: TSE suspect in, exp: experimentally infected, rel ratio: relative ratio, SD: standard deviation, mw: molecular weight, dig: di-glycosylated PrPres, mono: monoglycosylated PrP ${ }^{\text {res }}$, non: non-glycosylated PrP ${ }^{\text {res }}$.

flocks. The $K 222$ variant [10,16-18] was observed in five scrapie affected animals derived from two independent outbreaks and from two different scrapie endemic regions (A and J prefecture) (see Additional File 1); negative flockmates were unavailable. This variant was also found in negative goats, deriving from two of the five flocks analysed. Nucleotide polymorphisms at codons 21, 23, 49, 171 and 220 already reported in Greek goats $[7,8,14,18]$ were not observed during this survey.

Seventeen of the above caprine isolates originating from 11 affected flocks were tested by discriminatory immunoblotting, along with sheep flockmates from heavily affected mixed flocks i.e. one sheep from A4 and two from A11 (Table 2). Samples were selected with respect to available tissue for $\mathrm{WB}$ analysis and to be more or less representative of the country's whole territory. The isolates were from regions with high (flocks A2, A4, A9, A11, J1), intermediate (flocks L1, D1, E1, B1, F1) and low (flocks M1, N1) scrapie incidence
(Table 2) (see Additional file 1). Four Italian caprine isolates from four different flocks, an Italian sheep scrapie isolate and a sheep BSE sample were also included in the study.

Molecular typing of proteinase $\mathrm{K}$ resistant $\operatorname{PrP}\left(\mathrm{PrP}^{\mathrm{res}}\right)$ from positive cases was performed by ISS discriminatory WB [19] using the monoclonal antibodies SAF84 (residues 163-173 of ovine PrP; Spi-Bio, Montigny Le Bretonneux, France) and P4 (residues 89-104 of ovine PrP; RIDASCREEN, R-Biopharm, Germany). In each blot, an Italian sheep scrapie isolate and a sheep experimentally infected with BSE [20] were used as internal controls. The principle of discrimination of this testing strategy is based on the different $\mathrm{N}$-terminal cleavage for proteinase $\mathrm{K}$ digestion of PrP between sheep BSE and scrapie [21-26] which results in different apparent molecular mass of scrapie and BSE PrP ${ }^{\text {res }}$ and in the partial loss of the N-terminal amino acid sequence WGQGGSH in sheep BSE samples. For each sample, apparent molecular mass, SAF84/P4 ratio relative to the scrapie control 
and glycoform ratio were obtained from at least 3 independent determinations.

In immunoblots, caprine isolates showed apparent molecular masses and SAF84/P4 ratios similar to the scrapie control (Table 2, Figure 1). The mean apparent molecular mass $( \pm$ SD) for sheep BSE was $16.78 \pm 0.07$ $\mathrm{kDa}$, well lower than that observed for scrapie samples (from $17.51 \pm 0.04 \mathrm{kDa}$ to $18.04 \pm 0.02 \mathrm{kDa}$ ) (Table 2, Figure 2a). Similarly, the relative SAF84/P4 ratio for sheep BSE was $8.58 \pm 1.85$, while it was comprised between $0.38 \pm 0.01$ and $1.21 \pm 0.35$ in scrapie. The glycoform ratio also allowed a clear-cut discrimination of sheep BSE from all scrapie isolates (Figure 2b). Scrapie samples, indeed, were characterised by a lower ratio (from 48:31 to 55:29) than sheep BSE (71:20). Among scrapie samples, some Greek isolates showed a slightly higher apparent molecular mass and a slightly lower SAF84/P4 ratio compared to the other Greek and Italian isolates (Figure 2a). The six isolates, showing the highest apparent molecular mass of $\operatorname{PrP}^{\text {res }}$ and the lowest SAF84/P4 ratio, were two goats carrying K222 variant from flock A2 (GR-A2-G1 and -G2) and two sheep (GR-A11-S1 and -S2) and two goats (GR-A11-G1 and -G2) from flock A11 (Table 2, Figure 2a). When compared to all other scrapie isolates, these six scrapie cases showed a significantly higher apparent molecular mass $(17.92 \pm 0.05$ vs. $17.54 \pm 0.04, P=0.0002)$ and a significantly lower SAF84/P4 ratio $(0.48 \pm 0.04$ vs. $1.01 \pm 0.03$, $P<0.0001)$.

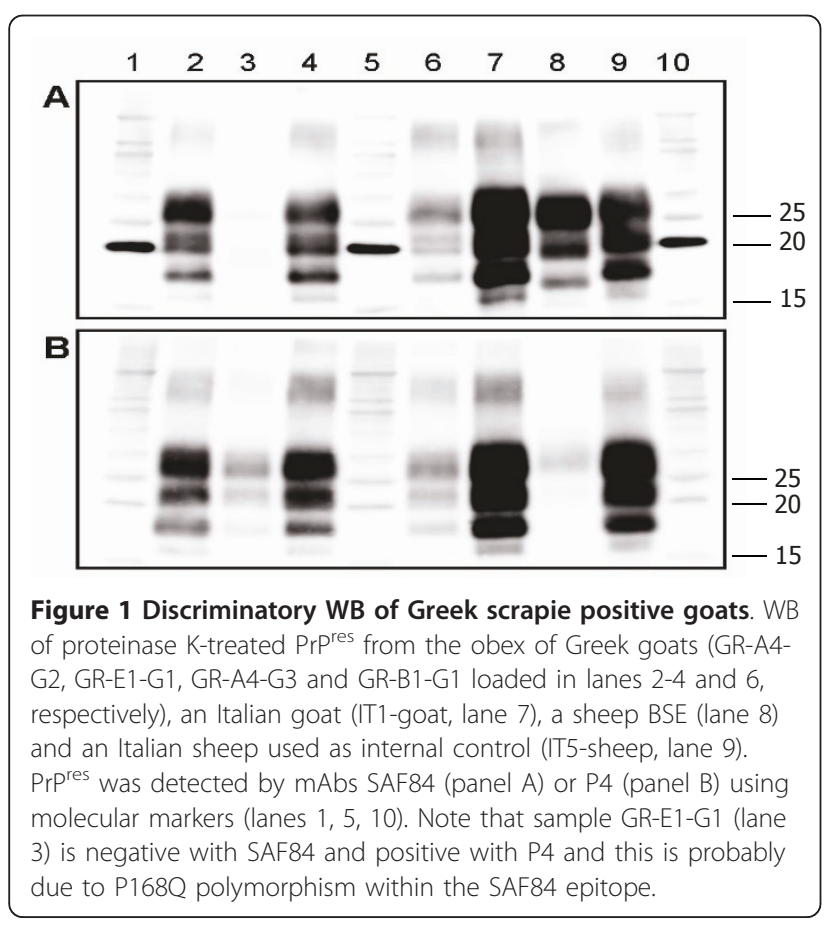

Noteworthy, a caprine sample (GR-E1-G1) did not react with SAF84, although it was positive with $\mathrm{P} 4$ (Figure 1). After $\operatorname{PrP}^{\text {res }}$ concentration, this sample was barely positive with SAF84 and strongly positive with P4 (data not shown). This prevented us from determining its molecular parameters (Table 2). Given that sample GR-E1-G1 was homozygous for Q at codon 168, which is comprised in the SAF84 epitope, we hypothesised that Q168 might hamper binding by SAF84. Indeed, another C-terminal mAb, L42, whose epitope does not include the amino acid residue 168, gave a clear scrapie positive immunoblot pattern (data not shown).

\section{Discussion}

In the present survey, extensive genotyping of scrapie positive goats from Greece and molecular isolate typing of caprine cases from regions with various prevalence of scrapie was performed. Since the present study is not a case control study, no clear association of the PrP genotype with scrapie susceptibility can be implemented, given that no flock data about the frequencies of $K 222$ and other alleles are available. Our findings demonstrate however a high PRNP genetic variability in Greek goats and the presence of novel nucleotide polymorphisms at codons 136 (A136T), 154 (R154Q), 173 (S173N) and 239 $(S 239 F)$. Moreover for the first time, the presence of N146S polymorphism in Greek scrapie negative goats was observed.

The observation of positive $K 222$ carriers in scrapie endemic areas was of particular interest. The cases were derived from three heavily scrapie infected flocks (A2, A4 and J1). Unfortunately, due to lack of flock data, we could not investigate whether $K 222$ carriers were subject to a strong infectious pressure in flocks with high scrapie prevalence or they were simply not protected from scrapie infection, possibly due to the involvement of a scrapie strain different from those previously studied in Italy and France $[10,16,17]$ or Greece [18].

The ISS discriminatory WB method allowed a clearcut biochemical discrimination of Greek goat scrapie isolates from BSE. The biochemical data of GR-E1-G1 sample brought us to conclude that Q168 homozygosis inhibits the antibody binding probably because of the SAF84 paratope-epitope mismatch. On this point, the polymorphic epitopes in goat $P R N P$ gene might reveal a potential negative impact on the performances of diagnostic and discriminatory testing of goat scrapie where anti-PrP antibodies are used $[27,28]$.

Interestingly, most of the Greek isolates showed molecular characteristics identical to Italian goat scrapie cases, while isolates from two outbreaks deriving from regions with high scrapie prevalence (flocks A2 and A11), including positive goats bearing the $K 222$ variant, showed slight but statistically significant 


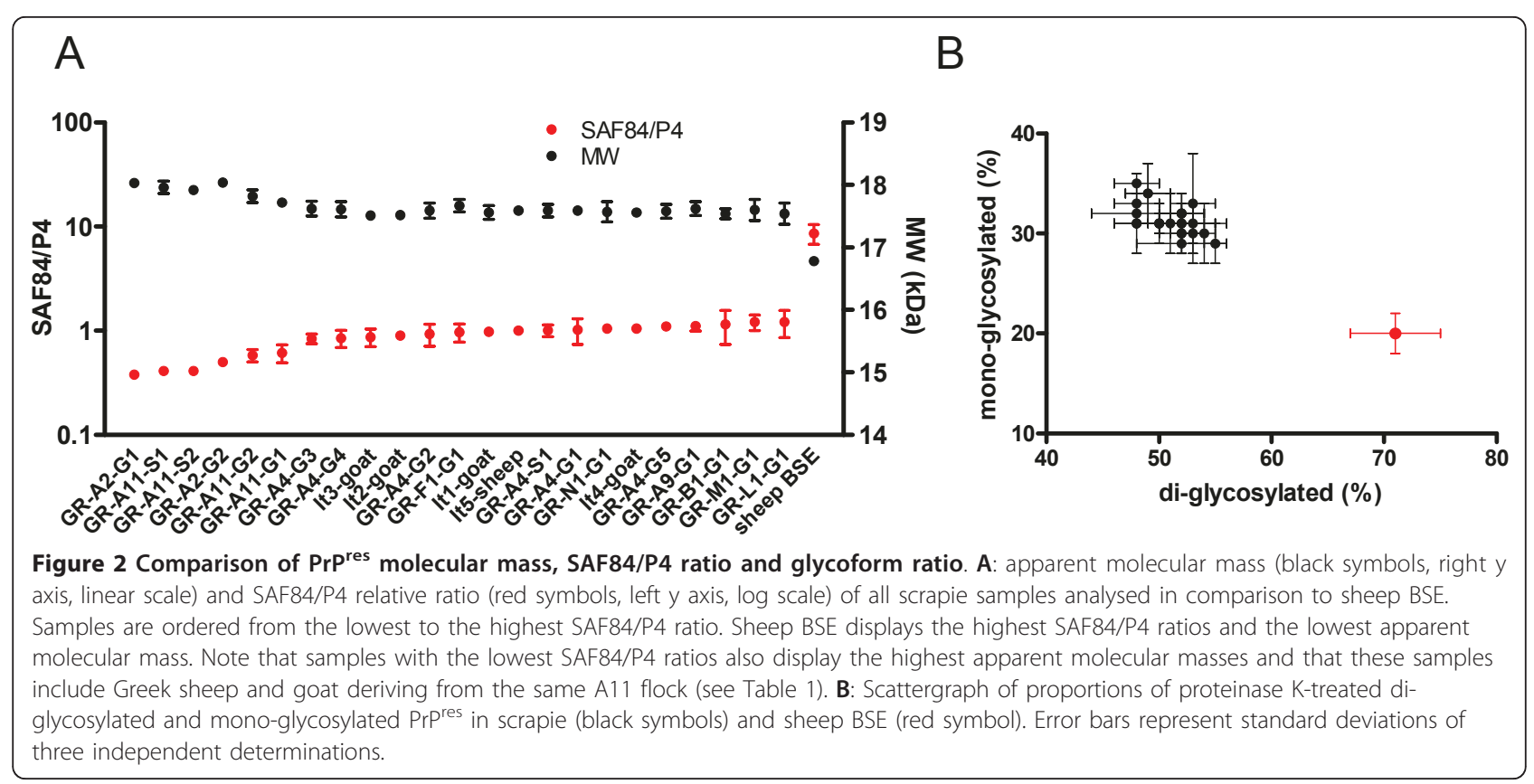

molecular differences compared to the other Greek and Italian isolates. Whether these molecular differences are indicative of the presence in those outbreaks of a different scrapie strain remains to be determined. The biological characterization of Greek isolates by bioassays in transgenic mice and bank voles is currently underway.

\section{Additional material}

Additional file 1: Geographic location of the scrapie positive goat flocks (number in parenthesis) tested per prefecture (capital letters). The number in parenthesis indicates the total number of flocks tested per prefecture (i.e. A (15) means 15 flocks tested from A region).

\section{List of Abbreviations}

TSE: transmissible spongiform encephalopathies; BSE: bovine spongiform encephalopathy; PrP: prion protein; PRNP: prion protein encoding gene; WB: western blotting; Prpres : proteinase $\mathrm{K}$ resistant prion protein

\section{Acknowledgements}

Acknowledgements are addressed to Dr Eleni Chartona-Koutsoukou, Chief Veterinarian of National Reference Laboratory for TSE, Larissa, Greece for providing us most of the goat samples and contributing to the implementation of this research. The first author acknowledges financial support from the Greek State Scholarship Foundation (I.K.Y.). The study was supported by the EU project Goat-BSE (FOOD-CT-2006-36353).

\section{Author details}

'National Agricultural Research Foundation, Veterinary Research Institute, Thessaloniki, Greece. ${ }^{2}$ Istituto Superiore di Sanità, Department of Veterinary Public Health and Food Safety, Rome, Italy. ${ }^{3}$ Aristotle University of Thessaloniki, Faculty of Veterinary Medicine, Clinic of Productive Animal Medicine, Thessaloniki, Greece.

\section{Authors' contributions}

$E L, F E, N R, V G, A U$ conceived the study, participated in its design and coordination. FE, VG, RN, LE helped to draft the manuscript. NG participated in the design of the study. FE, VG, CM, CB carried out the molecular genetic studies and participated in the sequence alignment. NR, EE, FE carried out the immunoblotting. All authors read and approved the final manuscript.

\section{Competing interests}

The authors declare that they have no competing interests.

Received: 26 March 2011 Accepted: 30 September 2011 Published: 30 September 2011

\section{References}

1. Baylis M, Goldmann W: The genetics of scrapie in sheep and goats. Curr Mol Med 2004, 4:385-396.

2. Agrimi U, Conte M, Morelli L, Di Bari MA, Di Guardo G, Ligios C, Antonucci G, Aufiero GM, Pozzato N, Mutinelli F, Nonno R, Vaccari G: Animal transmissible spongiform encephalopathies and genetics. Vet Res Commun 2003, 27:31-38.

3. Aguzzi A, Heikenwalder M, Polymenidou M: Insights into prion strains and neurotoxicity. Nat Rev Mol Cell Biol 2007, 8:552-561.

4. EFSA, Panel on Biological Hazards (BIOHAZ): Scientific Opinion on genetic TSE resistance in goats in all European Union Member States. EFSA J 2009, 7:1371.

5. Vaccari G, Panagiotidis $C H$, Acin C, Peletto S, Barillet F, Acutis P, Bossers A, Langeveld J, Van Keulen L, Sklaviadis T, Badiola JJ, Andréoletti O, Groschup MH, Agrimi U, Foster J, Goldmann W: State-of-the-art review of goat TSE in the European Union, with special emphasis on PRNP genetics and epidemiology. Vet Res 2009, 40:48.

6. Jeffrey M, Martin S, González L, Foster J, Langeveld JP, van Zijderveld FG, Grassi J, Hunter N: Immunohistochemical features of PrP(d) accumulation in natural and experimental goat transmissible spongiform encephalopathies. J Comp Pathol 2006, 134:171-181.

7. Sofianidis G, Psychas V, Billinis C, Spyrou V, Argyroudis S, Papaioannou N, Vlemmas I: Histopathological and immunohistochemical features of natural goat scrapie. J Comp Pathol 2006, 135:116-129.

8. Sofianidis G, Psychas V, Billinis C, Spyrou V, Argyroudis S, Vlemmas G: Atypical PrP ${ }^{s c}$ distribution in goats naturally affected with scrapie. $J$ Comp Pathol 2008, 138:90-101. 
9. European Commission: Cumulative TSE testing in goats since 2002. 2008 [http://ec.europa.eu/food/food/biosafety/bse/

mthly_gt_cml_reps_tse2002_en.pdf].

10. Vaccari G, Di Bari MA, Morelli L, Nonno R, Chiappini B, Antonucci G, Marcon S, Esposito E, Fazzi P, Palazzini N, Troiano P, Petrella A, Di Guardo G, Agrimi U: Identification of an allelic variant of the goat PrP gene associated with resistance to scrapie. J Gen Virol 2006, 87:1395-1402.

11. Vaccari G, Scavia G, Sala M, Cosseddu GM, Chiappini B, Conte M, Esposito E, Lorenzetti R, Perfetti G, Marconi P, Scholl F, Barbaro K, Bella A, Nonno R, Agrimi U: Protective effect of the AT137RQ and ARQK176 PrP allele against classical scrapie in Sarda breed sheep. Vet Res 2009, 40:19.

12. Papasavva-Stylianou P, Windl O, Saunders G, Mavrikiou P, Toumazos P, Kakoyiannis C: PrP gene polymorphisms in Cyprus goats and their association with resistance or susceptibility to natural scrapie. Vet J 2011, 187:245-250

13. Goldmann W, Chong A, Foster J, Hope J, Hunter N: The shortest known prion protein gene allele occurs in goats, has only three octapeptide repeats and is non-pathogenic. J Gen Virol 1998, 79:3173-3176.

14. Billinis C, Panagiotidis CH, Psychas V, Argyroudis S, Nicolaou A, Leontides S, Papadopoulos O, Sklaviadis T: Prion protein gene polymorphisms in natural goat scrapie. J Gen Virol 2002, 83:713-721.

15. Papasavva-Stylianou P, Kleanthous $M$, Toumazos $P$, Mavrikiou $P$, Loucaides $P$ : Novel polymorphisms at codons 146 and 151 in the prion protein gene of Cyprus goats, and their association with natural scrapie. Vet J 2007, 173:459-462.

16. Acutis PL, Bossers A, Priem J, Riina MV, Peletto S, Mazza M, Casalone C, Forloni G, Ru G, Caramelli M: Identification of prion protein gene polymorphisms in goats from Italian scrapie outbreaks. J Gen Virol 2006, 87:1029-1033.

17. Barillet $F$, Mariat $D$, Amigues $Y$, Faugeras $R$, Caillat H, Moazami-Goudarzi $K$, Rupp R, Babilliot JM, Lacroux C, Lugan S, Schelcher F, Chartier C, Corbière F, Andréoletti O, Perrin-Chauvineau C: Identification of seven haplotypes of the caprine PrP gene at codons 127, 142, 154, 211, 222 and 240 in French Alpine and Saanen breeds and their association with classical scrapie. J Gen Virol 2009, 90:769-776.

18. Bouzalas I, Dovas C, Banos G, Papanastasopoulou M, Kritas S, Oevermann A, Papakostaki D, Chatzinasiou E, Papadopoulos O, Seuberlich T, Koptopoulos G: Caprine PRNP polymorphisms at codons 171, 211, 222 and 240 in a Greek herd and their association with classical scrapie. J Gen Virol 2010, 91:1629-1634.

19. TSE strain characterisation in small ruminants. A technical handbook for national reference laboratories in EU. [http://www.defra.gov.uk/vla/ science/docs/sci_tse_rl_handbookv4jan10.pdf].

20. Nonno R, Esposito E, Vaccari G, Conte M, Marcon S, Di Bari MA, Ligios C, Di Guardo G, Agrimi U: Molecular analysis of cases of Italian sheep scrapie and comparison with cases of bovine spongiform encephalopathy (BSE) and experimental BSE in sheep. J Clin Microbiol 2003, 41:4127-4133.

21. Hope J, Wood SCER, Birkett CR, Chong A, Bruce ME, Cairns D, Goldmann W, Hunter N, Bostock CJ: Molecular analysis of ovine prion protein identifies similarities between BSE and an experimental isolate of natural scrapie, CH1641. J Gen Virol 1999, 80:1-4.

22. Baron TGM, Madec JY, Calavas D, Richard Y, Barillet F: Comparison of French natural scrapie isolates with bovine spongiform encephalopathy and experimental scrapie infected sheep. Neurosci Lett 2000, 284:175-178.

23. Stack MJ, Chaplin MJ, Clark J: Differentiation of prion protein glycoforms from naturally occurring sheep scrapie, sheep-passaged scrapie strains (CH1641 and SSBP1), bovine spongiform encephalopathy (BSE) cases and Romney and Cheviot breed sheep experimentally inoculated with BSE using two monoclonal antibodies. Acta Neuropathol 2002, 104:279-286.

24. Thuring $\mathrm{CM}$, Erkens $J \mathrm{H}$, Jacobs JG, Bossers A, van Keulen $\sqcup$, Garssen GJ, van Zijderveld FG, Ryder SJ, Groschup MH, Sweeney T, Langeveld JPM: Discrimination between scrapie and bovine spongiform encephalopathy in sheep by molecular size, immunoreactivity, and glycoprofile of prion protein. J Clin Microbiol 2004, 42:972-980.

25. Lezmi S, Martin S, Simon S, Comoy E, Bencsik A, Deslys JP, Grassi J, Jeffrey $\mathrm{M}$, Baron T: Comparative molecular analysis of the abnormal prion protein in field scrapie cases and experimental bovine spongiform encephalopathy in sheep by use of Western blotting and immunohistochemical methods. J Virol 2004, 78:3654-3662.
26. Gretzschel A, Buschmann A, Eiden M, Ziegler U, Lühken G, Erhardt G, Groschup MH: Strain typing of German transmissible spongiform encephalopathies field cases in small ruminants by biochemical methods. J Vet Med B Infect Dis Vet Public Health 2005, 52:55-63.

27. O'Rourke KI, Baszler TV, Besser TE, Miller JM, Cutlip RC, Wells GA, Ryder SJ, Parish SM, Hamir AN, Cockett NE, Jenny A, Knowles DP: Preclinical diagnosis of scrapie by immunohistochemistry of third eyelid lymphoid tissue. J Clin Microbiol 2000, 38:3254-3259.

28. O'Rourke Kl, Zhuang D, Truscott TC, Yan H, Schneider DA: Sparse PrP(Sc) accumulation in the placentas of goats with naturally acquired scrapie. BMC Vet Res 2011, 1:7.

doi:10.1186/1297-9716-42-104

Cite this article as: Fragkiadaki et al:: PRNP genetic variability and molecular typing of natural goat scrapie isolates in a high number of infected flocks. Veterinary Research 2011 42:104.

\section{Submit your next manuscript to BioMed Central and take full advantage of:}

- Convenient online submission

- Thorough peer review

- No space constraints or color figure charges

- Immediate publication on acceptance

- Inclusion in PubMed, CAS, Scopus and Google Scholar

- Research which is freely available for redistribution 